DOI: https://doi.org/10.24127/ajpm.v10i1.3392

\title{
PENGEMBANGAN MODUL MATEMATIKA BERBASIS KONTEKSTUAL PADA MATERI ALJABAR
}

\author{
Heni Pujiastuti $^{{ }^{*}}$, Rudi Haryadi ${ }^{2}$, Ely Solihati ${ }^{3}$ \\ ${ }^{1 *}, 2,3$ Universitas Sultan Ageng Tirtayasa, Banten, Indonesia \\ *Corresponding author. \\ E-mail: $\quad \frac{\text { henipujiastuti@untirta.ac.id }}{{ }^{*}{ }^{*}}$ \\ rudiharyadi@untirta.ac.id $^{2)}$ \\ $\underline{\text { elyslhti@gmail.com }}^{3)}$
}

Received 18 December 2020; Received in revised form 15 March 2021; Accepted 06 April 2021

\begin{abstract}
Abstrak
Tujuan pengembangan modul matematika berbasis kontekstual ini untuk mempermudah peserta didik dalam memahami materi aljabar. Penelitian ini adalah penelitian pengembangan dengan metode penelitian yang digunakan dalam penelitian ini adalah model ADDIE. Model ini terdiri dari lima buah tahapan yaitu assessment analysis, design, development, implementation dan evaluation. Subjek penelitian ini adalah siswa SMP kelas VII. Data yang diolah dalam penelitian ini dikumpulkan melalui lembar validasi ahli materi dan ahli media, serta angket respon siswa dengan skala likert. Berdasarkan keseluruhan penilaian produk oleh ahli materi diperoleh skor $85,4 \%$, yang termasuk dalam kriteria nilai sangat layak. Sedangkan keseluruhan penilaian produk oleh ahli media diperoleh skor 78,5\%, yang termasuk dalam kriteria nilai layak. Dari hasil yang didapatkan dari angket pernyataan terkait minat siswa terhadap modul mendapatkan skor rata-rata dari kesepuluh siswa tersebut yaitu 46.2. Berdasarkan dari hasil penilaian tersebut maka modul yang dikembangkan dengan pendekatan kontekstual dinyatakan sangat layak untuk digunakan pada pembelajaran materi aljabar serta dapat meningkatkan minat belajar siswa.
\end{abstract}

Kata kunci: Aljabar; kontekstual; minat belajar; modul matematika.

\begin{abstract}
The purpose of developing this contextual-based mathematics module is to make it easier for students to understand algebraic material. This research is a development research with the research method used in this study is the ADDIE model. This model consists of five stages, namely assessment analysis, design, development, implementation and evaluation. The subjects of this study were class VII junior high school students. The data processed in this study were collected through validation sheets of material experts and media experts, as well as student response questionnaires with a Likert scale. Based on the overall assessment of the product by material experts, it was obtained a score of $85.4 \%$, which is included in the very feasible score criteria. While the overall product assessment by media experts obtained a score of $78.5 \%$, which is included in the criteria for a decent score. And the results obtained from the questionnaire statement related to students' interest in the module got the average score of the ten students, namely 46.2. Based on the results of this assessment, the module developed with a contextual approach is declared feasible for use in learning algebraic material and it can increase student interest in learning.
\end{abstract}

Keywords: Algebra; contextual; learning interest; mathematics module. 
DOI: https://doi.org/10.24127/ajpm.v10i1.3392

\section{PENDAHULUAN}

\begin{tabular}{rrrr}
\multicolumn{2}{c}{ Kompetensi } & lulusan & pada \\
kurikulum 2013 & yang & perlu
\end{tabular} dikembangkan ada tiga yaitu karakter, pengetahuan, dan keterampilan yang relevan (Laal, Laal, \& Khattami, 2012; Pheeraphan, 2013; Thang et al., 2014). Artinya lulusan pendidikan harus menguasai kompetensi yang sangat berguna dalam hidup mereka (Abdullah \& Osman, 2010; Makaramani, 2015; van Laar, van Deursen, van Dijk, \& de Haan, 2019).

Pembelajaran matematika dalam praktek biasanya diawali dengan penjelasan konsep yang disertai contoh, diikuti dengan soal latihan (Barana \& Marchisio, 2016). Pendekatan pembelajaran ini didominasi oleh presentasi dari masalah matematika dalam bentuk tertutup dari masalah matematika yang dirumuskan sedemikian rupa hanya memiliki satu jawaban yang benar dengan satu solusi (Kuhl et al., 2020). Selain itu, masalah tertutup ini biasanya disajikan dalam secara terstruktur dan eksplisit, dimulai dengan apa yang diketahui, apa yang diminta, dan apa konsep digunakan untuk memecahkan masalah (Hardman, 2019).

Ide, konsep dan pola hubungan matematika sebagai serta strategi, teknik dan algoritma pemecahan masalah diberikan secara eksplisit, sehingga mahasiswa dapat dengan mudah menebak solusinya (BenavidesVarela et al., 2020). Pendekatan pembelajaran semacam ini cenderung hanya melatih keterampilan matematika dasar dengan cara yang terbatas dan terisolasi (Saleh, 2020).

Fakta lain yang ditemukan adalah bahwa masalah yang disajikan di kebanyakan buku tidak berhubungan dengan matematika konteks kehidupan sehari-hari sehingga pembelajaran matematika menjadi jauh dari kehidupan pelajar (Siregar, 2020). Dengan kata lain pembelajaran matematika menjadi kurang bermakna, sehingga dianggap sebagai penyebab rendahnya minat belajar matematika (Shulamit \& Yossi, 2011).

Salah satu alternatif pemecahan masalah yang telah dikemukakan adalah dengan mengembangkan modul matematika berbasis kontekstual. Dengan solusi ini, belajar memanfaatkan situasi dunia nyata, melibatkan siswa secara aktif, dan menghubungkan matematika dengan yang lain pengetahuan yang relevan (Fayomi, Okokpujie, Fayom, \& Okolie, 2019; Mcgrath \& Fischetti, 2019; van Laar et al., 2019). Pembelajaran memungkinkan siswa untuk membangun dan mengembangkan gagasan dan pemahaman tentang konsep matematika secara luas dan mendalam, memahami keterkaitan matematika dengan yang lain bidang ilmu pengetahuan, dan mampu diterapkan pada berbagai masalah kehidupan (Kusumaningsih, 2020; Saputri, 2020). Pendidikan matematika harus dikaitkan dengan konteks dunia nyata (Haryadi \& Pujiastuti, 2018).

Dengan mengembangkan suatu bahan ajar berupa modul matematika dengan karakteristik diharapkan dapat meningkatkan minat belajar siswa dan mempermudah siswa dalam belajar (Pujiastuti, Haryadi, \& Ridwan, 2020). Pembelajaran dengan menggunakan modul bertujuan (1) siswa mampu belajar secara mandiri atau dengan bantuan guru seminimal mungkin, (2) peran guru tidak mendominasi dan tidak otoriter dalam pembelajaran, (3) melatih kejujuran siswa, (4) mengakomodasi berbagai tingkat dan kecepatan belajar siswa, dan (5) siswa dapat mengukur sendiri tingkat penguasaan materi yang 
dipelajari (Pujiastuti \& Haryadi, 2019). Selanjutnya, dalam modul pembelajaran metode dan pendekatan pembelajaran harus disesuaikan dengan kurikulum yang berlaku (Pujiastuti, Utami, \& Haryadi, 2020).

Pada pelaksanaan pengembangan modul matematika berbasis kontekstual ini memilih topik atau materi aljabar. Aljabar merupakan salah satu cabang matematika yang mulai dipelajari secara formal oleh siswa tingkat Sekolah Menengah Pertama (SMP). Konsep aljabar didahului oleh aritmatika sebagai dasarnya. Dalam pembelajaran aljabar, pemahaman aritmatika yang baik sangat diperlukan (Safitri \& Pujiastuti, 2020). Ketika siswa dihadapkan langsung dengan halhal yang abstrak, siswa akan merasa kesulitan untuk memahaminya (Shulamit \& Yossi, 2011). Oleh karena itu, siswa diberikan pemahaman lebih pada sesuatu yang konkrit. Begitu pula dengan pembelajaran aljabar, siswa perlu pemahaman yang konkrit agar tidak mengalami kesulitan dalam materi aljabar.

Bahan ajar (modul) yang dibuat dengan menggunakan pendekatan kontekstual, disusun dengan menggunakan permasalahan dalam kehidupan sehari-hari serta membuat peserta didik menemukan sendiri sebuah konsep matematika. Dengan mengetahui keterkaitan materi yang dipelajari dengan kehidupan sehari-hari dapat memancing rasa ingin tahu peserta didik untuk belajar dengan baik sehingga dapat meningkatkan prestasi belajarnya (Pujiastuti, Haryadi, et al., 2020). Pendekatan kontekstual mempunyai tujuh komponen utama, yakni constructivism, inquiry, questioning, learning community, modeling, reflection, dan authentic assessment (Haryadi, 2015).
Dengan uraian tersebut, maka tujuan penelitian adalah untuk mengembangkan bahan ajar berupa modul pembelajaran materi aljabar dengan pendekatan kontekstual yang layak serta diharapkan dapat meningkatkan minat belajar siswa SMP.

\section{METODE PENELITIAN}

Penelitian ini adalah penelitian pengembangan dengan metode penelitian yang digunakan dalam penelitian ini adalah model ADDIE. Model ini terdiri dari lima buah tahapan yaitu assessment analysis, design, development, implementation dan evaluation (Arifin, Pujiastuti, \& Sudiana, 2020). Prosedur pengembangan media pembelajaran dideskripsikan pada bagan alir yang disajikan pada Gambar 1.

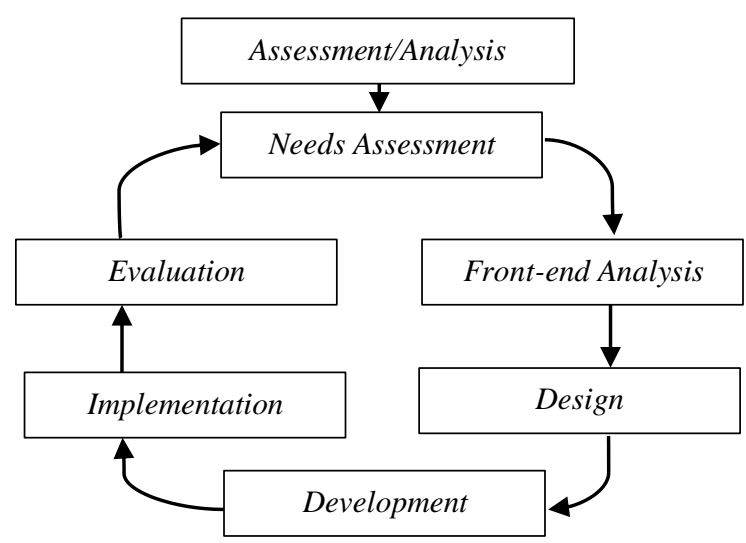

Gambar 1. Prosedur Pengembangan ADDIE

Tahapan awal dalam model ADDIE adalah tahap Assessment analysis, tahapan ini dilakukan untuk menganalisis masalah yang ada dan solusi yang tepat bagi untuk mengatasi masalah tersebut. Analisis yang dilakukan berkaitan dengan materi dan masalah yang dihadapi oleh siswa dan guru yang nantinya akan menjadi sasaran pengguna dari bahan ajar (modul) yang dibuat. Tahapan dari 
analisis adalah a) Analisis Kurikulum; b) Analisis Kebutuhan; c) Analisis Materi Pembelajaran dan; d) Merumuskan Tujuan.

Tahap design atau adalah tahap berpikir visual untuk mempersiapkan hal-hal yang dibutuhkan dalam mengembangkan modul pembelajaran. Tahap Development merupakan tahapan pelaksanaan rencana yang telah dibuat pada tahapan desain untuk menjadi sebuah produk yang akan diimplementasikan. Dilanjutkan dengan tahap Implementation yaitu tahapan pengujian terbatas kepada siswa untuk melihat bagaimana tanggapan dari siswa terhadap bahan ajar (modul) yang dibuat.

Tahap yang terakhir adalah tahap evaluation merupakan tahapan validasi dari ahli materi dan ahli pendidikan terhadap modul pembelajaran yang dikembangkan.

\section{HASIL DAN PEMBAHASAN}

Berdasarkan identifikasi awal telah diketahui bahwa guru perlu memodifikasi cara mengajar. Sehingga dibutuhkan sebuah alat dalam pembelajaran yang bisa mengatasi permasalahan tersebut yang berupa modul. Modul ini dapat membantu siswa untuk memahami materi sesuai dengan kemampuannya masingmasing dan memotivasi siswa dalam belajar.

Modul dibuat dengan menggunakan bahasa yang sederhana, warna dan gambar yang menarik, serta dibuat sebaik mungkin. Modul yang baik yaitu apabila modul telah layak digunakan dalam pembelajaran dan pada saat ujicoba terbatas modul tidak menimbulkan permasalahan, serta modul memperoleh respon positif dari siswa. Adapun tampilan sampul modul pembelajaran matematika yaitu seperti Gambar 2.

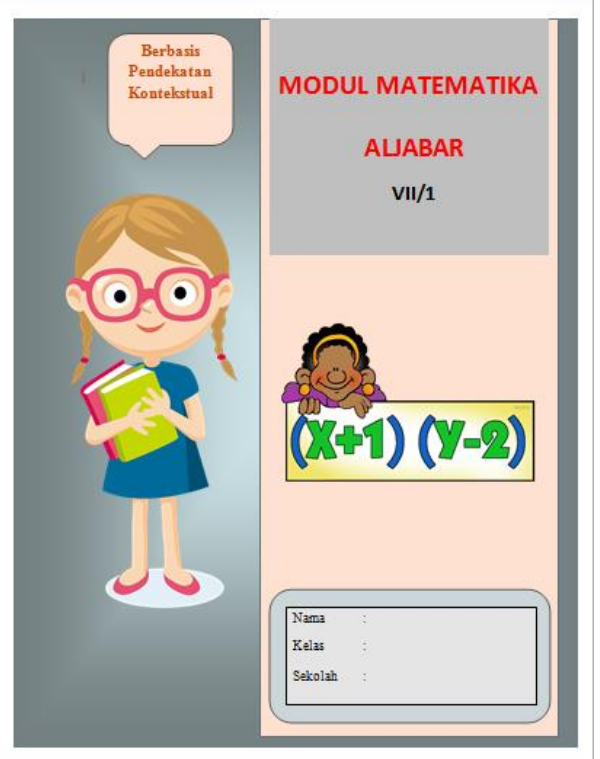

Gambar 2. Sampul modul pembelajaran

Berdasarkan kebutuhan siswa tersebut, maka perlu adamya pengembangan sebuah modul pembelajaran matematika pada materi operasi aljabar untuk siswa kelas VIII SMP/MTs. Modul pembelajaran telah divalidasi oleh dua validator, yaitu: 1 dosen pendidikan matematika dan 1 guru matematika. Hasil validasi dari validator menunjukkan tingkat kelayakan yang baik dan modul pembelajaran bisa diujicobakan. Berikut ini hasil dari langkah yang dilakukan dalam tahapan ADDIE.

Pada tahap analysis telah dilakukan pengamatan terhadap kompetensi yang akan dicapai pada materi aljabar yang akan dikembangkan pada modul terlebih dahulu. Analisis yang dilakukan meliputi analisis kompetensi yang akan dicapai, analisis karakteristik siswa SMP, serta analsis referensi yang akan digunakan sebagai acuan dalam penyusunan bahan ajar. Dalam tahapan ini dikembangan indikator 
capaian setiap materi pada aljabar. Hal ini bertujuan untuk mengukur tingkat kedalaman materi yang bertumpu pada kurikulum matematika dasar untuk siswa SMP. Dari tahapan ini diperoleh hasil untuk materi pokok aljabar pada mata pelajaranMatematika Dasar untuk siswa SMP.

Hasil analisis tujuan pembelajaran meliputi capaian pengetahuan, capaian sikap, dan capaian keterampilan. Selanjutnya dilakukan analisis terhadap karakteristik peserta didik. Pada langkah ini dilakukan pengamatan secara langsung ketika proses uji coba pembelajaran. Dengan adanya bahan ajar yang dikembangkan yaitu berupa modul diharapkan dapat membantu siswa dalam memahami konsep matematika terutama aljabar. Selain analisis tujuan pembelajaran dan karakteristik siswa, dilakukan analisis terhadap sumber yang akan digunakan sebagai acuan atau referensi dalam penyusunan modul.

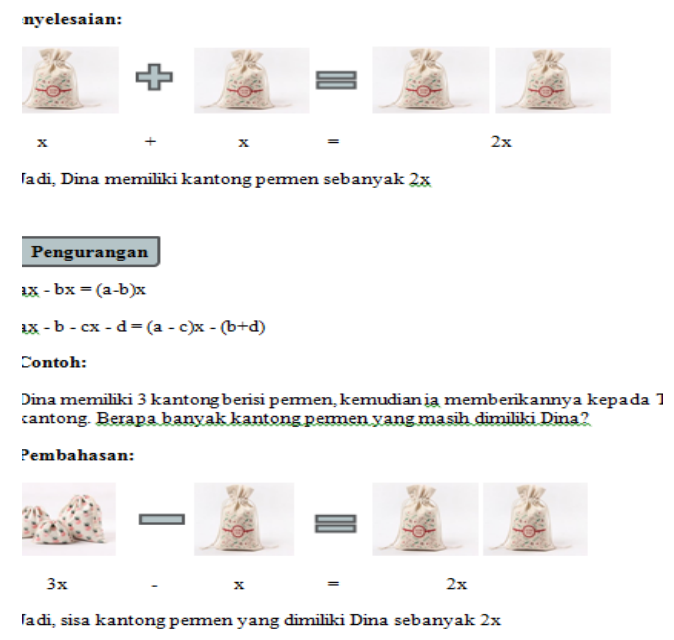

Gambar 3. Modul sebelum revisi.

Kegiatan yang dilakukan pada tahap design atau perencanaan pengembangan modul aljabar dengan pendekatan kontekstual meliputi penyusunan draf awal modul dan penyusunan instrumen yang digunakan. Berikut adalah salah satu hasil design pada pengembangan produk modul dapat dilihat pada Gambar 3.

Proses penyusunan draf awal modul dilakukan dengan menentukan kompetensi yang akan dicapai, kemudian menentukan judul setiap bab maupun subbab. Setelah draf awal produk selesai disusun, selanjutnya peneliti mengembangkan instrumen yang digunakan untuk evaluasi produk.

Instrumen yang digunakan antara lain yaitu lembar penilaian ahli materi, lembar penilaian ahli media, serta lembar penilaian respon siswa terhadap modul. Instrumen yang dikembangkan mengacu pada kajian teori yang ada serta sesuai dengan kebutuhan data yang akan diperoleh peneliti. Aspek yang dinilai oleh ahli materi terdiri dari aspek kelayakan isi, kelayakan penyajian, kelayakan bahasa dan penilaian kontekstual. Sedangkan untuk penilaian ahli media aspek yang dinilai terdiri dari ukuran modul, desain sampul, dan desain isi modul. Berikut salah satu penilaian ahli yang perlu direvisi dari modul yang dibuat.

Setelah dilakukan tahap development maka produk yang dikembangkan diujicobakan dalam kelompok kecil. Pada penelitian ini, tahap development adalah memperbaiki tahap dari design. hasil development dapat dilihat pada Gambar 4. Selanjutnya pada tahap implementation dilakukan uji coba penggunaan produk yang terhadap 10 siswa SMP. Agar lebih jelas mengetahui hasil minat belajar siswa terhadap matematika menggunakan modul tersebut dapat dilihat pada Tabel 1. 


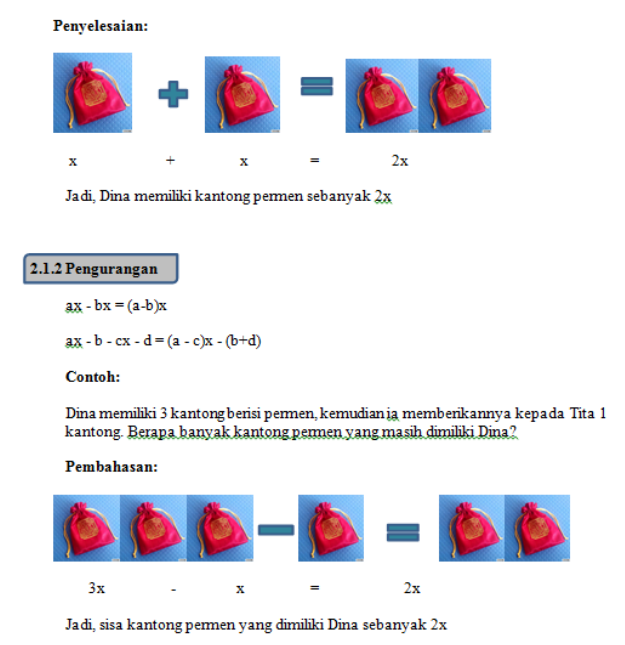

Gambar 4. Modul setelah revisi

Tabel 1. Hasil minat belajar.

\begin{tabular}{lll}
\hline Siswa & Skor & Keterangan \\
\hline Shandy R & 51 & Sangat Minat \\
Mitha A.P & 43 & Minat \\
Azka F & 41 & Minat \\
Faisal Albert & 44 & Minat \\
Antonio R & 48 & Minat \\
Suci Aulia & 45 & Minat \\
Hilda N & 48 & Minat \\
Raissa O & 48 & Minat \\
Ananda Dwi & 46 & Minat \\
Salsabila & 48 & Minat \\
Rata-rata & $\mathbf{4 6 . 2}$ & Minat \\
\hline
\end{tabular}

Berdasarkan analisa minat siswa terhadap modul matematika materi aljabar yang dilakukan sepuluh orang siswa SMP. Hasil didapatkan dari angket yang berupa pernyataan terkait minat siswa terhadap modul mendapatkan skor rata-rata dari kesepuluh siswa tersebut yaitu 46.2 dari skor maksimal 60 atau sebesar $77 \%$. Berdasarkan perhitungan yang sudah ada dengan hasil tersebut, maka modul berbasis pendekatan kontekstual yang telah dikembangkan dapat meningkatkan minat belajar matematika siswa khususnya pada materi aljabar. Dalam menganalisa minat siswa terhadap modul, siswa menuliskan kesan dan pesan terhadap modul yang telah digunakan. Melalui kesan dan pesan siswa dapat dilihat bahwa modul tersebut berpengaruh pada minat siswa dalam belajar matematika. Pada saat uji coba siswa diberikan produk untuk dipelajari. Namun, sebelumnya diberikan penjelasan terhadap bagian modul dan petunjuk dalam penggunaan modul tersebut.

Tahap terakhir dari model pengembangan ADDIE adalah tahap evaluation. Evaluasi yang dilakukan adalah evaluasi atau penialian dari ahli media seperti yagn disajikan apda Tabel 2 dan penilaian ahli materi seperti yang disajikan pada Tabel 3 .

Tabel 2. Hasil penilaian oleh ahli media

\begin{tabular}{llc}
\hline No & Aspek Penilaian & Skor \\
\hline 1 & Ukuran Modul & 7 \\
2 & Desain Sampul & 18 \\
& Modul (Cover) & 63 \\
3 & Desain Isi Modul & 88 \\
\hline \multicolumn{2}{r}{ Jumlah }
\end{tabular}

Hasil penilaian ahli media digunakan untuk menilai apakah media tersebut sudah layak dan dapat digunakan atau belum. Berdasarkan hasil Tabel 2, diketahui bahwa jumlah skor yang diperoleh dari uji ahli media adalah 88 dari skor maksimal 112 atau sebesar 78, 5\%. Hasil penilaian ahli materi digunakan untuk menilai apakah materi tersebut sudah sesuai atau belum.

Tabel 3. Hasil penilaian oleh ahli materi

\begin{tabular}{|c|c|c|}
\hline No & Aspek Penilaian & Skor \\
\hline 1 & Kelayakan Isi & 42 \\
\hline 2 & Kelayakan Penyajian & 23 \\
\hline 3 & $\begin{array}{c}\text { Kelayakan Bahasa } \\
\text { Menurut BSNP }\end{array}$ & 30 \\
\hline 4 & Penilaian Kontekstual & 28 \\
\hline
\end{tabular}

Berdasarkan hasil Tabel 3, diketahui bahwa jumlah skor yang diperoleh dari uji ahli materi adalah 123 
dari skor maksimal 144 atau sebesar 85, 4\%. Dari penilaian ahli media dan materi diperoleh rata-rata persentase sebesar $81,9 \%$, artinya modul pembelajaran materi aljabar dengan pendekatan kontekstual sangat layak digunakan untuk pembelajaran.

Hasil penilaian dari ahli digunakan untuk perbaikan modul sehingga menjadi modul yang layak digunakan bagi siswa sebagai salah satu referensi atau sember belajar. Selanjutnya berdasarkan penilaian respon siswa didapat bahwa secara keseluruhan kelayakan media pembelajaran modul matematika materi aljabar berbasis pendekatan kontekstual termasuk dalam kategori setuju sebesar $50 \%$ dengan rata-rata 3,28 . Hal ini menunjukkan bahwa media modul matematika materi aljabar berbasis pendekatan kontekstual telah memenuhi kriteria setuju untuk digunakan sebagai bahan ajar yang baik di SMP.

Dari hasil penelitian diperoleh bahwa penilaian produk oleh ahli materi dengan skor $85,4 \%$, yang termasuk dalam kriteria nilai sangat baik. Sedangkan keseluruhan penilaian produk oleh ahli media diperoleh skor $78,5 \%$, yang termasuk dalam kriteria nilai layak. Dari hasil penilaian tersebut maka modul yang dikembangkan dengan pendekatan kontekstual dinyatakan layak.

Temuan dalam penelitian ini yaitu menghasilkan suatu bahan ajar yang baru dan dapt digunakan pada siswa SMP. Berdasarkan hasil penelitian terhadap respon siswa, bahwa siswa tertarik (minat) belajar matematika ini melalui modul berbasis kontekstual. Siswa dapat memahami kejadian atau peristiwa yang berkaitan sehari-hari dengan menggunakan modul. Hasil dari penelitian ini merupakan penelitian pengembangan yang digunakan untuk menambah bahan ajar yang belum tersedia pada proses pembelajaran matematika, khususnya materi aljabar.

Kelebihan dari produk modul ini, yaitu terdapatnya materi-materi yang dilengkapi dengan peristiwa-peristiwa dalam keseharian siswa. Sehingga siswa dapat langsung mengkaitkan masalah matematika pada kehidupan sehari-hari. Sedangkan kelemahan dari modul ini yaitu, tidak dapat digunakan secara luas, karena materi yang dikaitkan harus sesuai dengan kondisi lingkungan siswa. Modul ini berdasarkan kontekstual pada kondisi lingkungan siswa setempat.

Hasil penelitian ini sejalan dengan (Pujiastuti, 2014) bahwa dengan pengembangan produk bahan ajar, siswa dapat lebih memahami konsep matematika. (Pujiastuti \& Fitriah, 2019) juga menyatakan bahwa, produk pengembangan dapat meningkatkan motivasi belajar, siswa merasa tidak bosan dengan produk bahan ajar yang sudah dikembangkan.

\section{KESIMPULAN DAN SARAN}

Dari hasil penelitian ini dapat disimpulkan bahwa bahan ajar berupa modul pembelajaran matematika berbasis kontekstual sangat layak untuk diterapkan dalam pembelajaran matematika terutama pada materi aljabar. Modul pembelajaran ini juga dapat meningkatkan minat belajar siswa.

Saran yang dapat diberikan kepada peneliti selanjutnya adalah: 1) harus lebih dipertimbangkan bagaimana nantinya efektifitas penggunaan modul pembelajaran yang telah dibuat, 2) harus dibuat modul pembelajaran serupa dengan materi yang lain agar tidak terbatas hanya untuk materi aljabar saja. 


\section{DAFTAR PUSTAKA}

Abdullah, M., \& Osman, K. (2010). 21st century inventive thinking skills among primary students in Malaysia and Brunei. Procedia Social and Behavioral Sciences, 9, 1646-1651.

https://doi.org/10.1016/j.sbspro.20 10.12 .380

Arifin, A. M., Pujiastuti, H., \& Sudiana, R. (2020). Pengembangan media pembelajaran STEM dengan augmented reality untuk meningkatkan kemampuan spasial matematis siswa. Jurnal Riset Pendidikan Matematika, 7(1), 5973.

Barana, A., \& Marchisio, M. (2016). Ten Good Reasons to Adopt an Automated Formative Assessment Model for Learning and Teaching Mathematics and Scientific Disciplines. Procedia - Social and Behavioral Sciences, 228(June), 608-613.

https://doi.org/10.1016/j.sbspro.20 16.07.093

Benavides-Varela, S., Zandonella Callegher, C., Fagiolini, B., Leo, I., Altoè, G., \& Lucangeli, D. (2020). Effectiveness of digital-based interventions for children with mathematical learning difficulties: A meta-analysis. Computers and Education, 157 (June). https://doi.org/10.1016/j.compedu. 2020.103953

Fayomi, O. S. I., Okokpujie, I. P., Fayom, G. U., \& Okolie, S. T. (2019). The challenge of Nigeria researcher in meeting up with the challenge of Nigeria researcher in meeting up with sustainable development goal in 21st century. Energy Procedia, 157, 393-404. https://doi.org/10.1016/j.egypro.20 18.11.204
Hardman, J. (2019). Towards a pedagogical model of teaching with ICTs for mathematics attainment in primary school: A review of studies 2008 - 2018 . Heliyon, 5(May), e01726. https://doi.org/10.1016/j.heliyon.20 19.e01726

Haryadi, R. (2015). Pembelajaran Kontekstual untuk Meningkatkan Kemampuan Pemecahan Masalah Fisika. Gravity: Jurnal Ilmiah Penelitian Dan Pembelajaran Fisika, 1(1).

Haryadi, R., \& Pujiastuti, H. (2018). Phet Simulation Software-Based Learning to Improve Understanding Ability in Light Concept. First International Conference on Technology and Educational Science. European Alliance for Innovation (EAI).

Kuhl, U., Friederici, A. D., Emmrich, F., Brauer, J., Wilcke, A., Neef, N., ... Skeide, M. A. (2020). Early cortical surface plasticity relates to basic mathematical learning. NeuroImage, 204(October 2019). https://doi.org/10.1016/j.neuroima ge. 2019.116235

Kusumaningsih, W. (2020). Uno stacko based on realistic mathematics: A developing learning media of trigonometry. Journal of Physics: Conference Series, Vol. 1663. https://doi.org/10.1088/17426596/1663/1/012044

Laal, M., Laal, M., \& Khattami, Z. (2012). 21st century learning; learning in collaboration. Procedia - Social and Behavioral Sciences, 47 , 1696-1701. https://doi.org/10.1016/j.sbspro.20 12.06.885

Makaramani, R. (2015). 21st Century Learning Design for a Telecollaboration Project. 
DOI: https://doi.org/10.24127/ajpm.v10i1.3392

Procedia - Social and Behavioral Sciences, 191, 622-627. https://doi.org/10.1016/j.sbspro.20 15.04.567

Mcgrath, J., \& Fischetti, J. (2019). What if compulsory schooling was a 21st century invention? Weak signals from a systematic review of the literature. International Journal of Educational Research, 95(April), 212-226.

https://doi.org/10.1016/j.ijer.2019. 02.006

Pheeraphan, N. (2013). Enhancement of the 21st Century Skills for Thai Higher Education by Integration of ICT in Classroom. Procedia Social and Behavioral Sciences, 103, 365-373. https://doi.org/10.1016/j.sbspro.20 13.10.346

Pujiastuti, H, \& Fitriah, F. (2019). Design of interactive teaching materials based on a scientific approach to support junior high school students' learning: Line and angles. Journal of Physics: Conference Series, 1157(3), 6-18.

Pujiastuti, H. (2014). Developing Teaching Material of Inquiry Cooperation Model for Enhancing Student'Mathematical

Communication Ability. International Seminar on Innovation in Mathematics and Mathematics Education. Universitas Negeri Yogyakarta

Pujiastuti, H., \& Haryadi, R. (2019). Interactive Math E-Book: An Alternative Learning Resources for 21st Century Learners. https://doi.org/10.4108/eai.21-112018.2282046

Pujiastuti, H., Haryadi, R., \& Ridwan, F. (2020). Development Of Mathematics Teaching Materials Based On Scientific Approach For
Mathematics Learning. AKSIOMA: Jurnal Program Studi Pendidikan Matematika, 9(3).

Pujiastuti, H., Utami, R., \& Haryadi, R. (2020). The development of interactive mathematics learning media based on local wisdom and 21 st century skills: social arithmetic concept. Journal of Physics: Conference Series. https://doi.org/10.1088/17426596/1521/3/032019

Safitri, A. I., \& Pujiastuti, H. (2020). Pengaruh Kemandirian Belajar Terhadap Hasil Belajar Matematika Siswa Smpn 1 Bojonegara Pada Materi Aljabar. Guru Tua: Jurnal Pendidikan Dan Pembelajaran, 3(1), 21-28.

Saleh, R. R. M. (2020). Analysis and design module based on PJBL to improve mathematical communication skills. Journal of Advanced Research in Dynamical and Control Systems, 12(7), 493501.

https://doi.org/10.5373/JARDCS/V 12I7/20202031

Saputri, R. R. (2020). Development of comic-based mathematics learning media on social arithmetic topic. Journal of Physics: Conference Series, Vol. 1657. https://doi.org/10.1088/17426596/1657/1/012082

Shulamit, K., \& Yossi, E. (2011). Development of E-Learning environments combining learning skills and science and technology content for junior high school. Procedia - Social and Behavioral Sciences, 11, 175-179. https://doi.org/10.1016/j.sbspro.20 11.01.056

Siregar, N. C. (2020). The effects of a discovery learning module on geometry for improving students' 
DOI: https://doi.org/10.24127/ajpm.v10i1.3392

mathematical reasoning skills, communication and selfconfidence. International Journal of Learning, Teaching and Educational Research, 19(3), 214228.

https://doi.org/10.26803/ijlter.19.3. 12

Thang, S. M., Sim, L. Y., Mahmud, N., Lin, L. K., Zabidi, N. A., \& Ismail, K. (2014). Enhancing 21st Century Learning Skills Via Digital Storytelling: Voices of Malaysian Teachers and Undergraduates. Procedia - Social and Behavioral Sciences, 118, 489-494. https://doi.org/10.1016/j.sbspro.20 14.02.067

van Laar, E., van Deursen, A. J. A. M., van Dijk, J. A. G. M., \& de Haan, J. (2019). Determinants of 21stcentury digital skills: A large-scale survey among working professionals. Computers in Human Behavior, 100(June), 93104.

https://doi.org/10.1016/j.chb.2019. 06.017 